\title{
Grids and Clouds in ITB
}

\author{
Basuki Suhardiman' \\ Institut Teknologi Bandung \\ Jalan Tamansari No. 64 Bandung, Indonesia \\ E-mail: basukilitb.ac.id
}

Before Grids and Clouds, Cluster Computing is the most used parallel computing system in Indonesia. One of the obstacles to overcome is that Universities in Indonesia do not have sophisticated infrastructure for doing the research. In ITB, for example, there are Clusters in some research groups that are used for specific purposes such as Weather Forecasting, computational Chemistry, and Molecular Computation.

The Grid Computing development in Indonesia was started in 2006 by several universities. The development continued when ITB joined EUAsiaGrid Project and connected Indonesia Grid to International Grid Infrastructures. Some research to port existing applications has been conducted but not yet able to deliver the expected result. Training also has been held to spread the knowledge on Grid Computing, in order to have more human resources that are able to administer grid systems and to use the grid to support their research activities.

Research on Grid computing focused on integrating the existing Cluster Computing to Grid Infrastructure. One Cluster has been successfully integrated as part of Grid ITB Site, but this cluster could not become production ready since it is being used by students to experiment the integration of the cluster to Grid Infrastructure. In order to stabilize the Grid Site, ITB is going to rebuild the ITB Grid Site system. The previous system has to be upgraded to be able to give better performance.

ITB has decided to build the grid infrastructure and cloud computing based on GPUs (Graphical Processing Unit) with 3200 GPU cores installed. Meanwhile for the application we are going to scale up the weather prediction models for Indonesia region.

Keyword: Grid and Clouds in ITB

The International Symposium on Grids and Clouds and the Open Grid Forum Academia Sinica, Taipei, Taiwan

March 19 - 25, 2011

\footnotetext{
$1 \quad$ Speaker
} 


\section{Introduction}

Grid and Cloud Computing is relatively new in Indonesia. Until now, cluster computing is the most widely used parallel computing system in Indonesia. However, Grid and Cloud computing could have more benefit rather than cluster computing system, although this is not applicable to all areas. Experiment on grid computing in Indonesia was started in 2008, and will be further developed to support areas that require high computational resources.

The Grid initiatives in Indonesia triggered by the development of Indonesia Higher Education and Research Network (Inherent) on 2006. With the limitation of the infrastructure in Indonesia, Inherent brought the concept of sharing the resources, including computing resources, of the Indonesian's Universities and Institutes.

Within the limit of resources such as knowledge to develop the grid computing, budget allocation for the research and grid operation, we are trying to move forward.

\subsection{Indonesian Grid (InGrid)}

InGrid, or Indonesian Grid infrastructure, has been developed by the University of Indonesia using UCLA Grid Portal consisting of Globus Toolkit 4 grid middleware and Gridsphere grid portlet framework. InGrid was triggered by Inherent (Indonesia Higher Education Network), the first NREN (National Research and Education Network) in Indonesia that connected almost 150 universities in Indonesia.

In 2008 two clusters have been connected to InGrid, one production cluster from the Faculty of Computer Science, University of Indonesia, and one research cluster. Applications available in the research cluster are:

$\begin{array}{ll}\text { Povray }(3.1 \mathrm{~g}) & - \text { gcc } \\ \text { MpiBLAST } & - \text { g77 } \\ \text { GNU Octave } & - \text { GROMACS }\end{array}$

There are some issues in developing Grid Computing in Indonesia, for example finding suitable grid applications and disseminating information to other communities in Indonesia. The Network Infrastructure and Hardware capacity that is currently available for Grid Computing is also a concern.

\subsection{ITB Grid Site}

The opportunity arose when ITB joined the Grid Community that connected Europe and Asia-Pacific e-Infrastructure. To provide access for local communities in Indonesia to this Europe and Asia-Pacific e-Infrastructure, ITB built a grid Site called ID-ITB site.

ID-ITB site is designed so that users in Indonesia are able to access grid resources to perform computations needed in their research, and also designed to provide services for users who want to port their existing applications so they can be run in the grid environment.

The platforms used in InGrid and ID-ITB is quite different. ID-ITB is using gLite middleware developed by EGEE as used by other partners incorporated in this Europe and AsiaPacific e-Infrastructure. 
Some of the researchers are experimenting on integrating their cluster into ID-ITB Site so that the cluster resources can also be made available in the EUAsiaGrid infrastructure. Dozen 2010 is the first cluster in ITB that was integrated to the grid infrastructure. This cluster is managed by the Engineering Physics Department. Dozen 2010 is a cluster system based on Rock Cluster connected to EUAsiaGrid infrastructure using gLite middleware. In Dozen 2010, gLite Computing Element is installed on the front-end node, while the gLite Worker Node are installed on VM in the cluster's compute node. The integration process is currently providing practice materials for students in Engineering Physics.

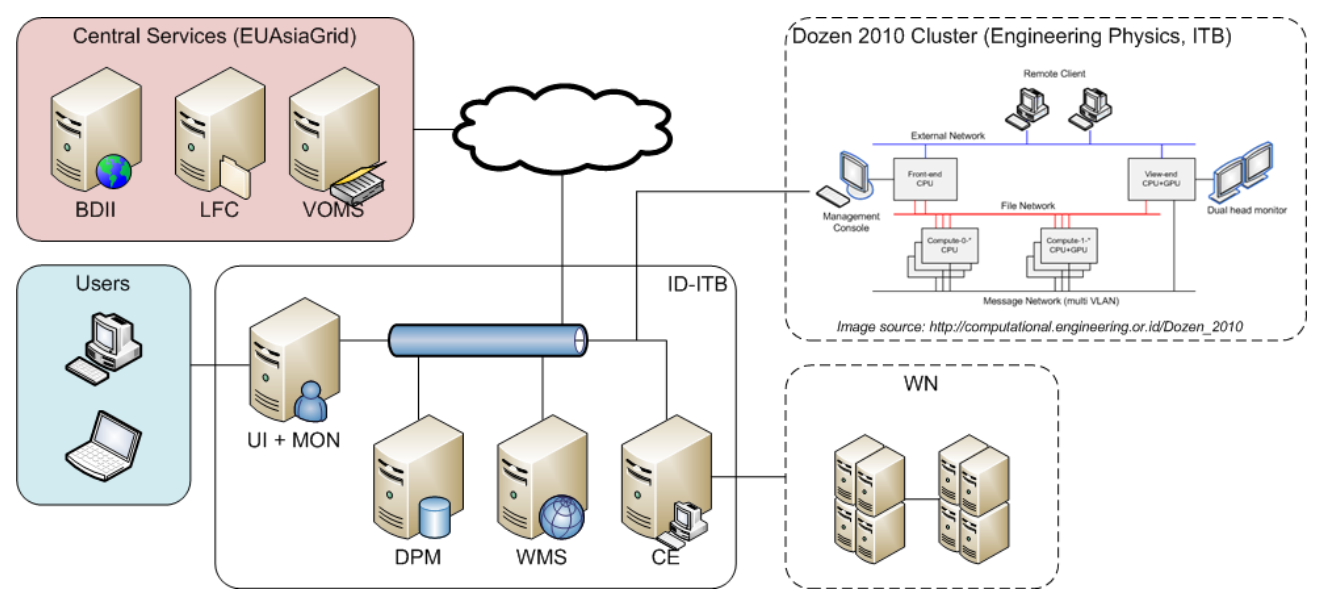

ID-ITB site last configuration

\section{Development of Local Application}

Most user communities have their own applications. Some of them run the application on cluster systems. Grid infrastructure offers more computing power than is currently available local cluster systems. However, in order to be able to run the applications in a grid environment, the applications need to be ported to the grid.

\subsection{Weather Forecast}

The Weather Forecast application in ITB is managed by the Atmospheric Science Research Group in the Faculty of Earth Sciences and Technology. The current application used for Weather Forecast is WRF running on Cluster with Open Suse 10.3 as the Operating System. Using Grid Infrastructure, an experiment to implement WRF4G (WRF for Grid) that has been developed by University of Cantabria under EELA2 will be conducted. However, the WRF4G implementation could not yet be performed due to follow up from the University of Cantabria.

Grid infrastructure are expected to be able to support research performed using Numerical Weather Prediction (NWP) so that the prediction for Southeast Asia region can be made using very high resolution weather modeling. There is the need to consider some specific requirements to run WRF application on grid infrastructure. For example, the relatively large number of file size and library files needed. The library files must be compiled using the same compiler that is used to compile the WRF application. In addition, prior to running the 
application we must know whether there are worker nodes which have the exact same library files needed by the application. And when there are no worker nodes that are compatible with the required library file, we will need to know how to make the library files needed available on the grid Infrastructure. Another problem is that we need the MPI compiler.

The Weather forecast team has installed the new two GPU machines, each having two Intel 5500/5600 Xeon with Quad Core, with QPI up to $6.4 \mathrm{GT} / \mathrm{s}$ and 1 NVIDIA M2050 GPU card enterprise level 4 x 448 CUDA cores. The Operating system is RedHat 5.5 and installs WRF and CAM (climate model) on one machine. The CAM used for the climate model is especially for tropical country (Indonesia). Obstacles for these experiments were the limitation on MPI for GPU and compiler for GPU.

\subsection{Disaster Mitigation}

The focus area for Disaster mitigation is Hazard map for the mitigation and the vulnerabilities. The Hazard map focus on the seismic hazard map, earthquake hazard map, and information hazard map for the mitigation (human population). The vulnerabilities focus on the risk impact factors and risk area for infrastructure such as road, electricity, water and other impact to the pupulation. The development of this domain need for digitization, modeling and visualization in data processing that demands Grid-enabled high performance computing.

In Disaster mitigation field, the support is planned to cover volcanoes and Firewatch (forestry).

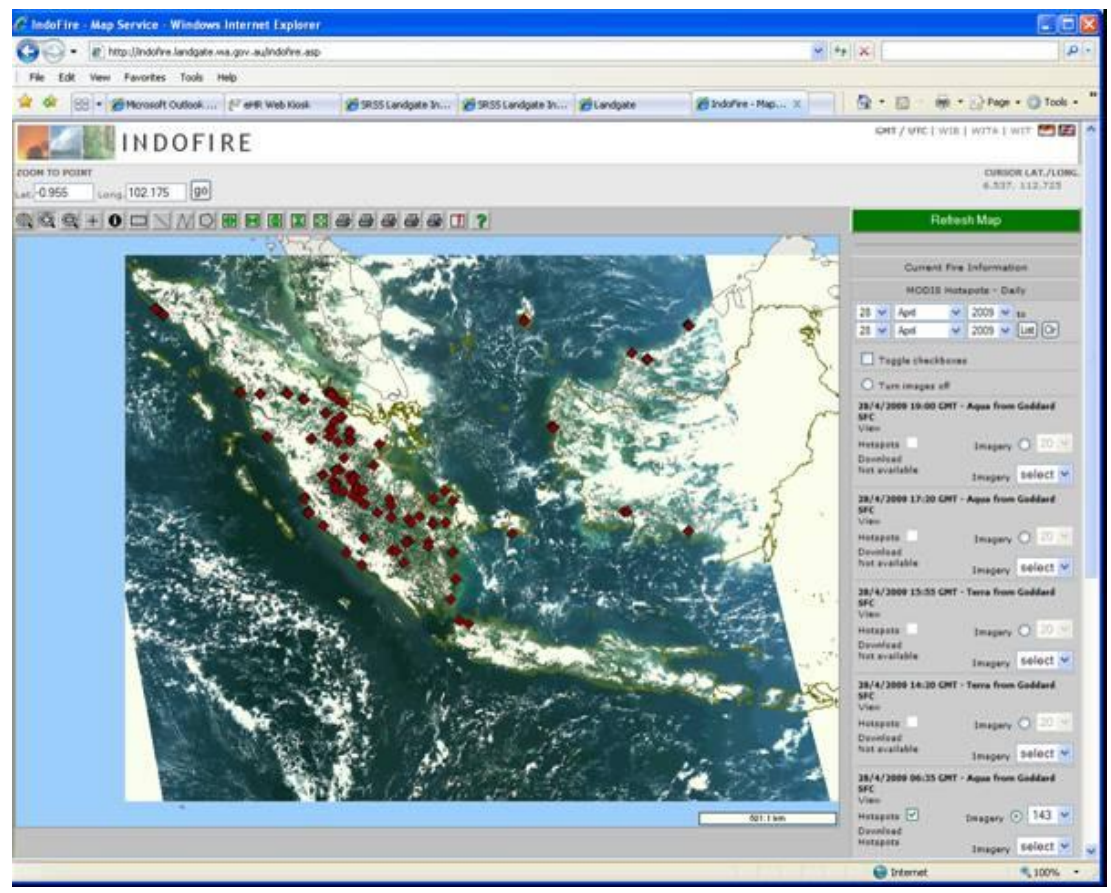

Example of Firewatch application

Firewatch has been initiated by the Ministry of Forestry, Ministry of Environment, National Space Agency /LAPAN (Lembaga Penerbangan dan Antariksa Nasional) and cooperated with Government of Australia /LANDGATE. The data is received in Australia, Pare-pare (Indonesia) and Jakarta (headquarters). The data is received in MODIS data format 
and it is collected in Australia and Pare-pare. The data analyzed using several servers in a cluster system. The data delivered every 12 hours and could be used to generate a map of the hotspot area for the Ministry of Forestry headquarter and regional office.

\subsection{Digital Library}

A Digital Library is a management system for library resources (text, audio, and video) in digital format. There are more than 50 universities networks running that provide online access using Internet and NREN. Inherent Network is utilized to build Indonesia Digital Library Network (Indonesia DLN) with other Universities in Indonesia.

The Digital Library development was started in 1999; meanwhile the initiative to develop Indonesia DLN was started in 2000. And now, we are going to develop Grid enabled GDL where Grid can be utilized, for example, for indexing process, and storage.

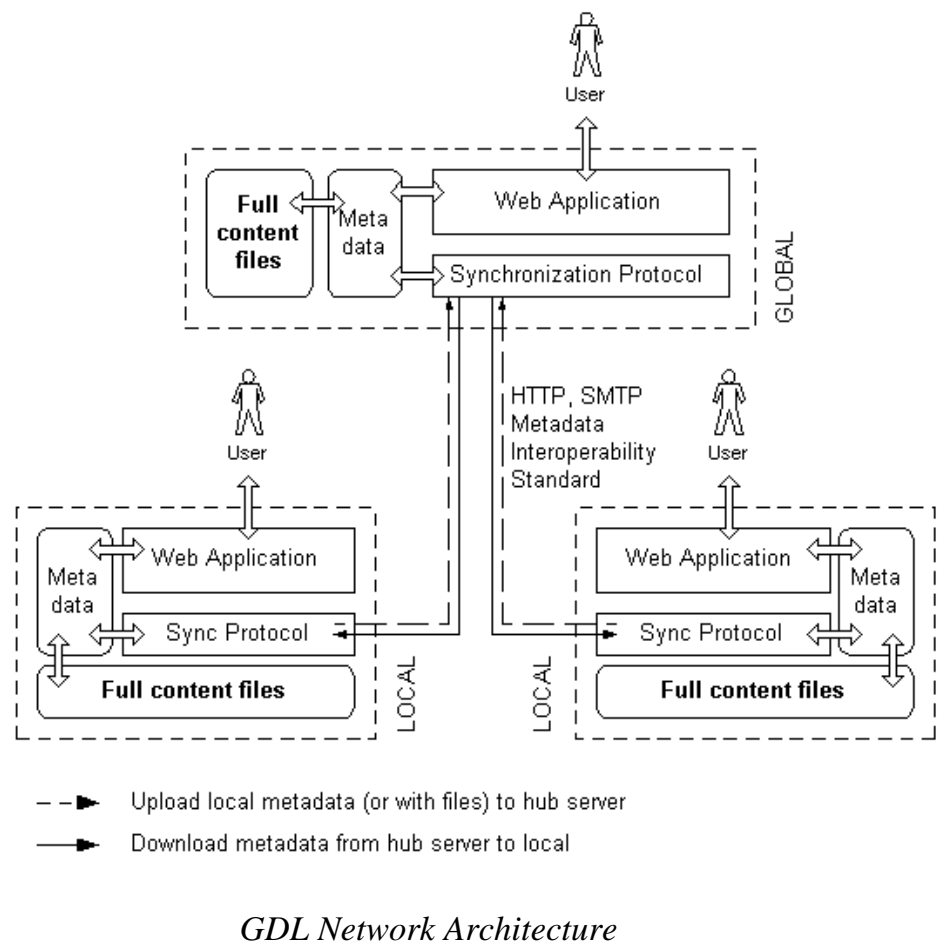

For next step, we will port the GDL source to the grid enable using GLite.

\section{Conclusion and Future Plan}

To develop grid computing in Indonesia, dissemination is the keyword. Knowledge on grid technology need to be extended to other universities so that more people become aware of Grid Infrastructure and Grid Applications, and are able to access Grid Resources available and more people interested and join the development of Grid and Grid Application. 


\section{References}

[1] A. Voss, EUAsiaGrid, escience, pp.360-361, 2008 Fourth IEEE International Conference on eScience, 2008.

[2] B.A.A. Nazief, RI-GRID: Usulan Pengembangan Infrastruktur Komputasi Grid Nasional, Prosiding e-Indonesia Initiative 2006. 